\title{
Postural Control in Children with Developmental Coordination Disorder
}

\author{
Reint H. Geuze \\ Developmental \& Clinical Neuropsychology, University of Groningen, The Netherlands
}

\begin{abstract}
The development of static balance is a basic characteristic of normal motor development. Most developmental motor tests include a measure of static balance. Children with Developmental Coordination Disorder (DCD) often fail this item. This study reviews the balance problems of children with DCD. The general conclusion is drawn that under normal conditions static balance control is not a problem for children with DCD. Only in difficult, unattended, or novel situations such children seem to suffer from increased postural sway. These findings raise the question of what happens when balance is lost. The present study addresses the strength of correlation between the electromyography (EMG) and force plate signals in one-leg stance over epochs of stable and unstable balance. Four groups of children were involved in the study: two age groups and a group of children with DCD and balance problems and their controls. The results show a clear involvement of tibialis anterior and peroneus muscles in the control of lateral balance in all conditions and groups. The group of children with DCD and balance problems, however, showed a weaker coupling between EMG and corrective force compared with control children, indicating non-optimal balance
\end{abstract}

Reprint requests to: Dr. R.H. Geuze, Developmental \& Clinical Neuropsychology, Grote Kruisstraat 2-1, 9712 TS Groningen, The Netherlands; e-mail: R.H.Geuze@RUG.NL control. An evaluation of the existing data in terms of evidence of specific structural deficits associated with DCD provided converging evidence that suggests cerebellar involvement.

\section{KEYWORDS}

clumsiness, balance, loss of balance, force plate, EMG

\section{INTRODUCTION}

Not too long ago, evolution brought us upright stance, which opened new possibilities for functional behavior but also posed new problems for the control of locomotion and balance. Infants are not born with such capacities. In the first place, infants lack the strength for upright posture (Thelen et al., 1984). Additionally they completely lack experience with the pull of gravity and with vision, two sources of sensory information that are intimately involved in control of posture. Then there is the use of sensory feedback, which is essential for postural control. In a fully developed motor system, it is multi-modal and redundant, and intrinsically intertwined with anticipatory action, generating the reactive forces that are needed to counteract the-potential-loss of balance. The main sensory systems that are involved in the control of balance are the visual, kinesthetic, and vestibular systems, and pressure receptors of the somatosensory system. From a developmental point of view, the degree of postural control and 
balance acts as a constraint on the development of specific motor skills. Development of postural control has been extensively described in the work of Woollacott and Shumway-Cook (e.g. ShumwayCook \& Woollacott, 1985; 1990). In the present study, I will review problems of balance control in children with Developmental Coordination Disorder (DCD) and present data of an analysis of short epochs of stable and unstable balance selected from trials of one-leg stance.

\section{DEVELOPMENTAL COORDINATION DISORDER}

Developmental Coordination Disorder is a classified disorder of problems in motor development (DSM-IV, APA, 1994). DCD can be briefly defined as 'poor motor performance in daily activities that is not consistent with the child's age and intelligence, and is not due to a medical condition'. The DSM-IV classification of DCD is commonly assumed equivalent to the Specific Developmental Disorder of Motor Function (SDDMF) in the ICD-10 classification (WHO, 1992). Swedish researchers (e.g. Gillberg \& Gillberg, 1988) use the term DAMP (deficits in perceptual, attentional, and motor function) in addition to other categories of disorders, such as DCD and ADHD (attention deficit hyperactivity disorder). The authors point at the common cooccurrence of ADHD, DCD, and perceptual deficits, the prevalence of purer cases of $A D(H) D$ and DCD being less than that of DAMP (Landgren et al., 1996). In any case, there is no clear evidence of neurological impairment in these children, although the problems may reflect a non-optimal form of brain function, such as in minor neurological dysfunction (MND) (Hadders-Algra, 2003). The prevalence of DCD is 3 percent to 6 percent, with 2 to 3 times as many boys than girls affected.

The DSM classification of DCD explicitly states that the condition significantly interferes with activities of daily living or academic achieve- ment or both. A review of 41 case studies of DCD (aged 4 to 16 years) lists, in order of reported frequency, dressing (e.g. tying shoelaces), drawing and writing, locomotion, constructional play and the use of cutlery and scissors, speech, and ball skills/outdoor play as the major activities in daily living and school work that meet limitations (Geuze, 2005a,b). These limitations obviously are age dependent, as the 4-year-old child will not have yet learned to write. Balance and postural control are assumed fundamental to many of these tasks.

The main characteristics of DCD in the motor domain are poor postural control (moderate hypotonia or hypertonia, poor distal control, static and dynamic balance), difficulty in motor learning (learning new skills, planning of movement, adaptation to change, automatization), and poor sensorimotor coordination (coordination within/ between limbs, sequencing of movement, use of feedback, timing, anticipation, strategic planning). Consequently, such children are slow, inaccurate, non-fluent, and variable in their movements (Geuze, 2005b). A general taxonomic distinction in the motor domain is that between gross and fine motor skills, with balance control specifically related to gross motor skill. The well-known Movement Assessment Battery for Children (M-ABC test, Henderson \& Sugden, 1992) uses these classes of motor skills and has a further distinction between static and dynamic balance skills. These two types of balance are only weakly correlated, the former being more constrained compared with the latter because with a fixed base of support, the possibilities for a correction of loss of balance are much more limited.

It has been argued that perceptual difficulties are the cause of the motor problems in DCD (Laszlo \& Bairstow, 1993). A meta-analysis of Wilson and McKenzie (1998) showed that DCD is associated with poor visual perception only in tasks involving visual-spatial processing, whether or not the task involved a motor component. A link 
to pure visual perceptual deficits could not be demonstrated. A second outcome of the metaanalysis was a somewhat weaker association with kinesthetic sensitivity. Vision and kinesthesis are important sources of feedback in the control of balance.

From these characteristics of DCD, one should not conclude that children with DCD have, to a large extent, a similar pattern of deficits. These children are not a homogeneous group. On the contrary, the common finding is that only about half the children are affected in a specific skill or function (Geuze et al., 2001). Correlations between specific motor tasks are usually weak, which implies that the child can fail on certain motor tasks and succeed on others, suggesting that there may be subgroups with a more homogeneous set of symptoms, possibly with a common underlying defect. A review of studies that used cluster analysis of performance on 5 to 6 motor tasks (including static balance) (Visser, 2004) shows that typically 4 to 5 subtypes of DCD are found. Apart from a subtype that is poor on all tasks, another subtype is found with specific problems in about half the tasks, including static balance.

From the above it is clear that postural control and balance is one of the domains of perceptual motor performance in which many children with DCD can be impaired. The present study addresses the question: in what respect is the control of static balance different between control children and children with DCD. As this disorder does not permit a reliable diagnosis before the age of 5 years, I will concentrate on the age range of 5 to 12 years.

\section{A review of static balance control in children with DCD}

The control of static balance has been studied in children by using force plate or kinematic recordings, sometimes in combination with electromyography (EMG) measures. This approach has been used for both spontaneous sway in a standard posture and responses to an external mechanical or visual perturbation. As a background for the evaluation of the atypical characteristics of balance control in children with DCD, a brief outline of development of static balance in typically developing children is presented, followed by an exhaustive review of static balance research in DCD.

\section{Development of static balance in typically developing children.}

Until the age of 3 years, development of static balance is characterized by early visual predominance that gradually gives way to a greater involvement of somatosensory and vestibular input up to the age of 10 years, when a more adult like type of control is reached (Foudriat et al., 1993; Shumway-Cook \& Woollacott, 1985). This development is paralleled, between 4 and 8 years, by a decreasing level of EMG activity in most postural muscles measured in different postures: lower trapezius, pectoralis major, posterior deltoid, erector spinae, tibialis anterior, gastrocnemius, peroneus longus and semitendinosus, but not in upper trapezius, teres major and rectus abdominis (Williams et al., 1983). In that age range, with perturbation of posture a transition is found from variable to structured response synergies (Shumway-Cook \& Woollacott, 1985, 1990) and adaptations to sensory conditions improve (Foudriat et al., 1993). Forssberg and Nashner (1982) evaluated automatic postural adjustments to anterior and posterior displacements and rotations of the support surface and visual compensation for postural sway from recordings of torque, sway, and EMG responses of gastrocnemius, tibialis anterior, hamstrings and quadriceps muscles. Seventeen children aged $1 \frac{1}{2}$ to 10 years participated in the study.

Younger children (aged 11/2 to $7 \frac{1}{2}$ years, $n=$ 14) qualitatively showed responses similar to those 
of adults, even when deprived of specific sensory input. The children, however, showed greater variability and could not suppress systematically the influence of inputs derived from the support surface or from vision when these provided inappropriate orientation information, due to the motion of the platform. For standing on two legs, measures of postural sway show a rapid decline of postural sway between 3 and 6 years, and a slower one up to the age of 11 years (Usui et al., 1995). A longitudinal study of static balance in children aged 5 to 10 years revealed a transition around the age of 6 years in the postural sway velocity of the centre of pressure, a marker of strategy of reactive forces to loss of balance ( Kirshenbaum et al., 2001).

For standing on one leg, a fast decline is found between 6 and 9 years, and a slower one up to the age of 11 years (Usui et al., 1995). Anticipatory postural control, preceding voluntary arm movement while standing, is mature by 4 to 6 years (Shumway-Cook \& Woollacott, 1985, 1990).

From this brief overview, it can be concluded that automatic postural control improves up to the age of about 10 years, with qualitative changes at the level of integrated processing of sensory input around the age of 6 years, and improvement of dealing with conflicting sensory input up to the age of 8 years.

\section{POSTURAL SWAY, VISUAL FEEDBACK AND DCD}

The problems of balance and postural control of children with DCD may now be evaluated against this background of normal development. Recently a number of studies appeared that specifically addressed postural control and static balance in children with DCD (see Table 1).

Forseth and Sigmundsson (2003) measured the time to loss of balance in children selected for hand-eye coordination problems. This group can be considered a subgroup of DCD. The average duration of standing on one leg in balance decreased dramatically when closing the eyes and when balancing on a beam compared to the floor, both in the DCD-HECP group (vision vs no-vision floor 32 vs $9 \mathrm{~s}$, beam 11 vs $3 \mathrm{~s}$ ) and the control group (vision vs no-vision floor 50 vs $21 \mathrm{~s}$, beam 24 vs 4 s). The control group was able to maintain balance considerably longer than the DCD-HECP group. On the floor with vision, the non-preferred leg contributed to the group difference only in the condition stork stand.

Wann et al. (1998) studied postural sway by recording the head movement of the subjects while standing with eyes open and with eyes closed. The investigators did not find an age effect, but children with DCD $(n=6)$ displayed significantly more postural sway than matched controls $(n=6)$ in the condition eyes closed. Comparing vision to novision, the mean peak-peak amplitude in AP direction increased in 3 control subjects and in 4 children with DCD. Remarkably, the other subjects (showing a decrease of AP sway without vision) were those with the largest sway amplitude in the eyes-open condition.

Geuze (2003) and Przysucha and Taylor (2004) used force-plate measurements while standing with eyes open and closed. The authors specifically selected a subgroup of DCD: children with DCD and balance problems (DCD-bp). For quiet standing on two legs, Geuze found only a slightly increased sway for the DCD-bp group that was not significant: for lateral and AP directions, the increase was $4.7 \%$ and $6.6 \%$ respectively. For quiet standing on two feet, Przysucha and Taylor reported slightly increased lateral sway $(9 \%, \mathrm{~ns})$, and significantly increased AP sway (25\%) and area of COP $(42 \%)$ in the DCD-bp group. The Romberg coefficient (sway without vision relative to sway with vision) was not found to differentiate between groups in the two studies. Thus, the three studies indicate equal dependence on vision for the control of quiet standing with eyes open and eyes closed. 
TABLE 1

Characteristics of six studies addressing the differences in postural control between children with and without DCD

\begin{tabular}{|c|c|c|c|c|c|c|}
\hline study & $\mathbf{N}$ & groups $^{*}$ & age & task /-variables & measures & $\begin{array}{c}\text { major sign. problems } \\
\text { in DCD }\end{array}$ \\
\hline $\begin{array}{l}\text { Forseth \& } \\
\text { Sigmundsson } \\
2003\end{array}$ & $\begin{array}{l}12 \\
12\end{array}$ & $\begin{array}{l}\text { DCD-HECP (estimated } \\
<15^{\text {th }} \text { perc) } \\
\text { non-DCD -HECP } \\
\text { (estimated }>15^{\text {th }} \text { perc) }\end{array}$ & $\begin{array}{l}10-11 y \\
10-11 y\end{array}$ & $\begin{array}{l}\text { one-leg stance } \\
\text { - vision yes/no } \\
\text {-leg: pref. vs } \\
\text { non- } \\
\text { - floor vs beam }\end{array}$ & $\begin{array}{l}\text { time to loss of } \\
\text { balance }\end{array}$ & $\begin{array}{l}\text { control group kept } \\
\text { balance longer }\end{array}$ \\
\hline Geuze 2003 & $\begin{array}{l}24 \\
24 \\
16 \\
\\
24\end{array}$ & $\begin{array}{l}\text { DCD }<15 \text { th perc. } \\
+ \text { balance problems } \\
\text { non-DCD }>10^{\text {th }} \text { perc } \\
\text { and } 2 \text { age groups: } \\
\text { younger group } \\
\text { older group }\end{array}$ & $\begin{array}{l}6-12 y \\
6-12 y \\
6-7 y \\
10-12 y\end{array}$ & $\begin{array}{l}\text { stand still } \\
-1,2 \text { legs } \\
\text { - vision yes/no } \\
\text { - perturbation }\end{array}$ & $\begin{array}{l}\text { sway lateral \& } \\
\text { AP } \\
\text { EMG } \\
\text { recovery time }\end{array}$ & $\begin{array}{l}\text { - in 1-leg stance more } \\
\text { lateral sway and more } \\
\text { dependence on vision } \\
\text { - EMG more co- } \\
\text { contraction } \\
\text { - only slight problems } \\
\text { in 2-leg stance and } \\
\text { adaptation to } \\
\text { perturbation of stance }\end{array}$ \\
\hline $\begin{array}{l}\text { Johnston et } \\
\text { al. } 2002\end{array}$ & $\begin{array}{l}32 \\
32\end{array}$ & $\begin{array}{l}\text { DCD }<15^{\text {th }} \text { perc. } \\
\text { non-DCD }>15^{\text {th }} \text { perc } \\
+ \text { reference data }\end{array}$ & $\begin{array}{l}8-10 y \\
8-10 y\end{array}$ & $\begin{array}{l}\text { stand + arm lift } \\
-L, R \text { arm }\end{array}$ & $\begin{array}{l}\text { EMG timing } \\
\text { and activation }\end{array}$ & $\begin{array}{l}\text { lack of anticipatory } \\
\text { postural muscle } \\
\text { activation and poor } \\
\text { timing }\end{array}$ \\
\hline $\begin{array}{l}\text { Przysucha \& } \\
\text { Taylor } 2004\end{array}$ & $\begin{array}{l}20 \\
20\end{array}$ & $\begin{array}{l}\text { DCD }<5 \text { th perc. } \\
\quad+\text { balance problems } \\
\text { non- } D C D>15^{\text {th }} \text { perc }\end{array}$ & $\begin{array}{l}6-11 y \\
6-11 y\end{array}$ & $\begin{array}{l}\text { stand still } \\
\text { - vision yes/no }\end{array}$ & $\begin{array}{l}\text { sway lateral \& } \\
\text { AP }\end{array}$ & $\begin{array}{l}\text { dependence on vision } \\
\text { not different between } \\
\text { groups }\end{array}$ \\
\hline $\begin{array}{l}\text { Wann et al. } \\
1998\end{array}$ & $\begin{array}{l}6 \\
6 \\
6 \\
6\end{array}$ & $\begin{array}{l}\text { DCD }<5 \text { th perc. } \\
\text { non-DCD } \\
\text { nursery } \\
\text { adults }\end{array}$ & $\begin{array}{l}10-12 y \\
10-12 y\end{array}$ & $\begin{array}{l}\text { stand still } \\
\text { vision yes/no } \\
\text { amplitude of } \\
\text { swinging room }\end{array}$ & $\begin{array}{l}\text { sway AP } \\
\text { amplitude } \\
\text { coupling and } \\
\text { phase diff. }\end{array}$ & $\begin{array}{l}\text { - DCD more postural } \\
\text { sway without vision, } \\
\text { but non-conclusive for } \\
\text { entrainment } \\
\text { - large individual } \\
\text { differences }\end{array}$ \\
\hline $\begin{array}{l}\text { Williams et al. } \\
1983\end{array}$ & $\begin{array}{l}6 \\
14 \\
\end{array}$ & $\begin{array}{l}\text { DCD (mot.awkward) } \\
\text { no motor problems }\end{array}$ & $\begin{array}{l}4,6,8 y \\
4,6,8 y\end{array}$ & $\begin{array}{l}\text { static postures } \\
7 \text { postures } \\
12 \text { muscles } \\
\end{array}$ & $\begin{array}{l}\text { EMG average } \\
\text { amplitude }\end{array}$ & $\begin{array}{l}\text { DCD higher EMG } \\
\text { activation levels }\end{array}$ \\
\hline
\end{tabular}

Note: * Percentiles indicate cut-off criterion of the M-ABC test score for group selection. indicates a group of children selected for hand-eye coordination problems (HECP) selected or a sum score $>10$ on 5 items of the M-ABC test.

Wann et al. (1998) addressed the visual dependence more specifically by using a swinging room. When the environment moves slowly (in the frequency range of normal postural corrections (.1 to $1 \mathrm{~Hz}$ ), this movement can entrain postural sway, a phenomenon termed visual-induced sway. Nursery children were found to depend upon vision as a major source of postural information, whereas older children did not. Two DCD children clearly showed postural control problems and visual 
dependence similar to the nursery children. The other four did not differ from the control children.

Compared with quiet standing on two legs, standing on one leg resulted in an increase in AP and lateral sway (Geuze, 2003). Not surprisingly, it is the lateral control of balance differentiating the groups. In the eyes open condition, the DCD group had $35 \%$ larger sway in this direction than did the control group. In the eyes-closed condition, this difference increased up to $70 \%$ (interaction significant) after selecting the successful epochs when the children were in balance. It should also be noted that children with DCD-bp failed the task significantly more often (i.e. could not maintain one-leg balance) than the control children did.

We can conclude that difficulties in balance control show up more clearly with greater task constraints. Developmental Coordination Disorder is associated with larger postural sway and with failing more difficult balance tasks. For the majority of such children, this problem seems not to be due to greater dependence on vision.

\section{MUSCLE CONTROL IN CHILDREN WITH DCD}

Williams et al. (1983) recorded EMG activity of upper and lower trapezius, pectoralis major, teres major, posterior deltoideus, rectus abdominis, erector spinae, semitendinosus, tibialis anterior, soleus, gastrocnemius, and peroneus longus muscles in seven different static postures, such as lying down prone on elbows, pivot prone, on all fours, full kneel, half kneel, normal standing, and standing on one leg. The authors found large individual differences, but on average motorically awkward children displayed greater amounts of muscular activity than did control children matched for age, specifically in the lower trapezius, posterior deltoid, rectus abdominis, gastrocnemius, and peroneus longus muscles. Moreover, the gradual decrease of activation level did not decrease in the atypical children between the age of 4 and 8 years. It should be noted that these results are based on a qualitative evaluation of the recorded EMG, i.e. without calibration of the force-EMG relationship.

Johnston et al. (2002) studied anticipatory postural adjustments in response to voluntary arm movement (lifting the straight arm) to a visual target. The muscles investigated included the anterior deltoid, upper and lower trapezius, serratus anterior, latissimus dorsi around the shoulder girdle, and of the trunk the internal oblique muscles bilaterally, external oblique muscle contralaterally, rectus abdominis, and erector spinae. Children with DCD demonstrated altered muscle timing during voluntary goaldirected pointing, when compared with the nonDCD group. The authors demonstrated that, relative to the activation of the anterior deltoid muscle, children with DCD activated only two of five trunk muscles (contralateral internal oblique, erector spinae) in the anticipatory period ( -50 to $+150 \mathrm{~ms}$ around anterior deltoid onset). All four anterior trunk muscles were later in onset. Shoulder muscles (except serratus anterior) and the posterior trunk muscle, erector spinae, showed earlier activation. Children with DCD were also slower to respond to the visual stimulus and to complete the movement to the goal. The authors conclude that these data support the hypothesis that altered postural muscle activity can contribute to poor proximal stability and consequently to poor upper limb coordination of children with DCD.

Geuze (2003) studied differences in EMG activation patterns between children with and without DCD. In the DCD group, when children were well within balance while standing on one leg, co-contraction between the tibialis anterior and the peroneus muscles involved in controlling the ankle joint occurred 2.2 times more often, and slightly more significant peak activations were found in these muscles. In two-leg stance, when balance was unexpectedly perturbed by a ball lightly hitting the back, no difference between the 
groups was found for muscular response onset, amplitude of response, and recovery time over repeated trials. Only the first response was different, with longer recovery times for the DCD group. It is concluded that under normal conditions, static balance control is not a problem for children with DCD. Only in novel or difficult situations are such children at risk for losing balance. It is suggested that an analysis of sway and EMG just before losing balance might shed light on why children with DCD tend to lose their balance sooner and more frequently than control children do.

Losing balance: correlational analysis between EMG and force plate responses

Epochs of stable and unstable balance of children with and without DCD and balance problems were compared on balance control. Children were selected from three primary schools. Teachers selected one or two children who, in the teacher's opinion, were worst in the class in general motor skills and who might have balance problems. The teachers were asked to check their choice with the physical education (PE) teacher if the school had one. For the control group, one or two children from the same class were selected by random choice (see Geuze 2003 for details). The unaffected children consisted of a younger group $(\mathrm{n}=12 ; \mathrm{m} / \mathrm{f} 8 / 4)$ aged 6.0 to 8.3 years and an older group $(\mathrm{N}=14 ; \mathrm{m} / \mathrm{f} 7 / 7)$ aged 9.1 to 11.6 years. From these groups, a control group was selected $(n=13 ; \mathrm{m} / \mathrm{f} 9 / 4)$ with an age range of 6 to 11 years (mean age 9.0 years) that was matched for age and nearly for gender with the children with DCD-bp $(\mathrm{n}=13 ; \mathrm{m} / \mathrm{f} 10 / 3)$. None had severe learning difficulties, from which it may be assumed that the IQ was over 80 . All children participated in the study of Geuze (2003).

The motor performance of the children was tested at school with the Dutch version of the Movement-ABC test (Henderson \& Sugden, 1993; Smits-Engelsman, 1998). The selection criteria for the children with $\mathrm{DCD}$ and balance problems (DCD-bp) were (i) $\mathrm{M}-\mathrm{ABC}$ score $\leqq 15^{\text {th }}$ centile; (ii) $\mathrm{M}-\mathrm{ABC}$ balance subscore $>2$; (iii) $\mathrm{M}-\mathrm{ABC}$ static balance score $>1$. The average $\mathrm{M}-\mathrm{ABC}$ score for the control group was 4.5 (range 1.5-8) and for the DCD-bp group 15.6 (range 8.5-30.5). A typical example of the recordings and displacement of the center of pressure is shown in Fig. 1.

Control of balance when standing still on one leg for 10-30 s was analyzed by cross-correlation of the lateral and AP force plate signals (Fx and Fy) with the muscle activation of the tibialis anterior, peroneus, rectus femoris and semitendinosus muscles. The main function of the peroneus muscle in one-leg stance is to control AP sway, but the muscle also has a lateral component. The tibialis anterior muscle is mainly involved in the control of lateral sway, but has also a small AP component. rectus femoris flexes the hip and semitendinosus flexes the shank and retracts the thigh. The EMG's were filtered $(60-1000 \mathrm{~Hz})$ and converted into a true RMS signal $(0-35 \mathrm{~Hz})$. Force plate signals were filtered low-pass at $10.5 \mathrm{~Hz}$. These signals were sampled at $100 \mathrm{~Hz}$.

From each recording, one epoch of $10 \mathrm{~s}$ was selected, usually from 5 to $15 \mathrm{~s}$ after the beginning, and 3 further epochs of $1.5 \mathrm{~s}$. These were epochs when the child was (1) in balance; (2) unstable in balance; (3) close to losing balance; as evident from the path of the Center of Pressure (CoP) in this epoch. The cross-correlation between EMG and force plate signals was calculated over these 4 epochs.

Cross-correlation between EMG and force signals should incorporate delays from the electromechanical coupling in the muscle (typically $50 \mathrm{~ms}$ ) and transfer of force from the muscle through soft tissues to the force plate. These two were estimated together from adult reactive responses to voluntary loss of balance in AP or in lateral direction to be 50 to $60 \mathrm{~ms}$. With children being slower $(70$ to $80 \mathrm{~ms}$, Raynor, 1999) the delay time for the analysis was set at $80 \mathrm{~ms}$. Eventual perceptual-motor delay of the 

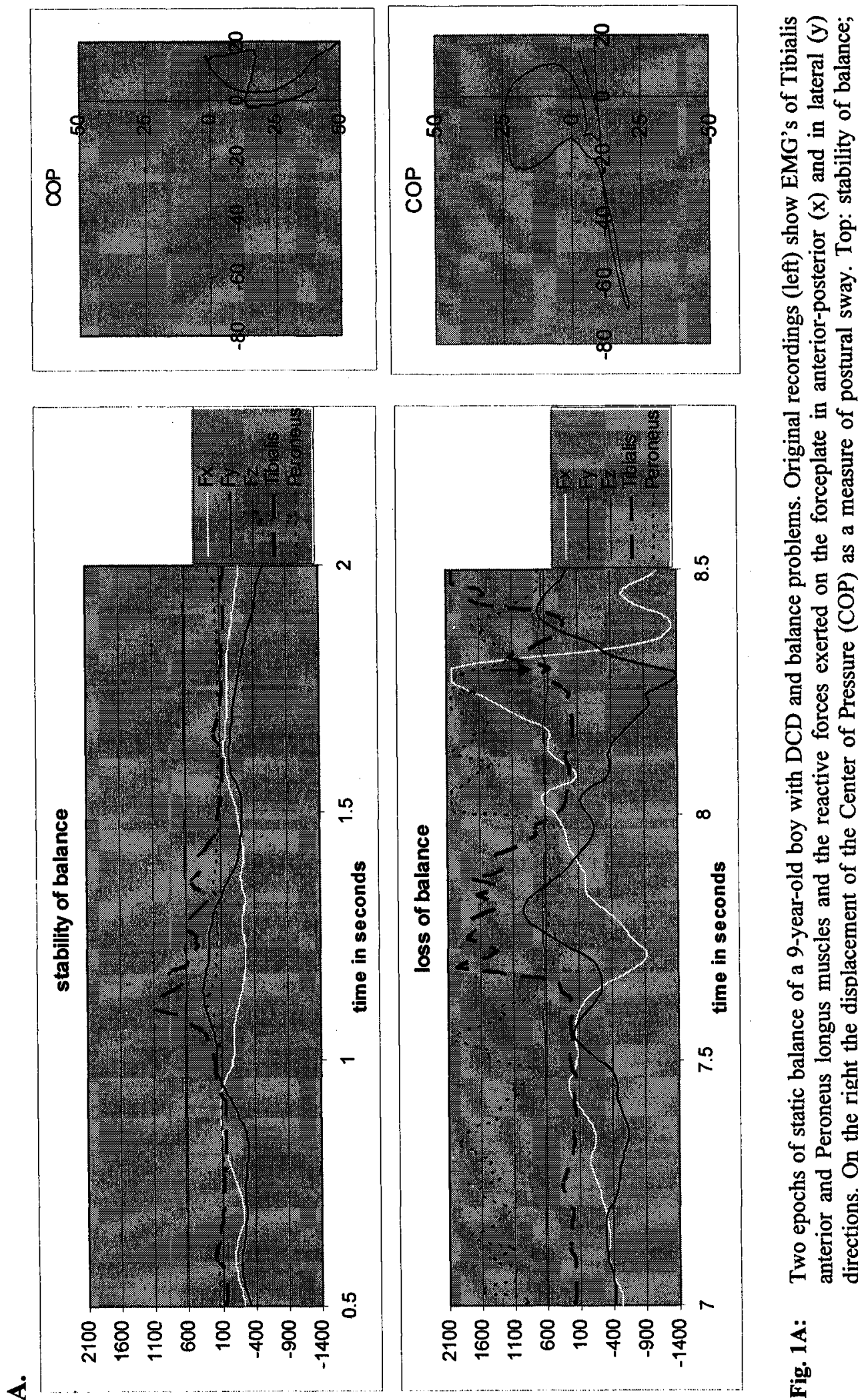

격.5

옳

吉各 巻

เ 응

응 웜

형

ษ

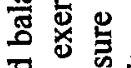

豆边忽

응 㛡

今点

昰总豆

๖

중월

긍 뭉

\&

ò 弟

本畐

约

寻哭号

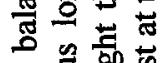

.

宽

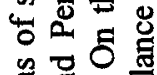

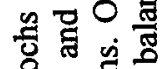

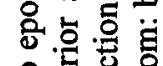

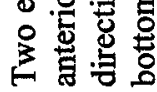

$\underset{2}{0}$ 
POSTURAL CONTROL IN CHILDREN WITH DCD
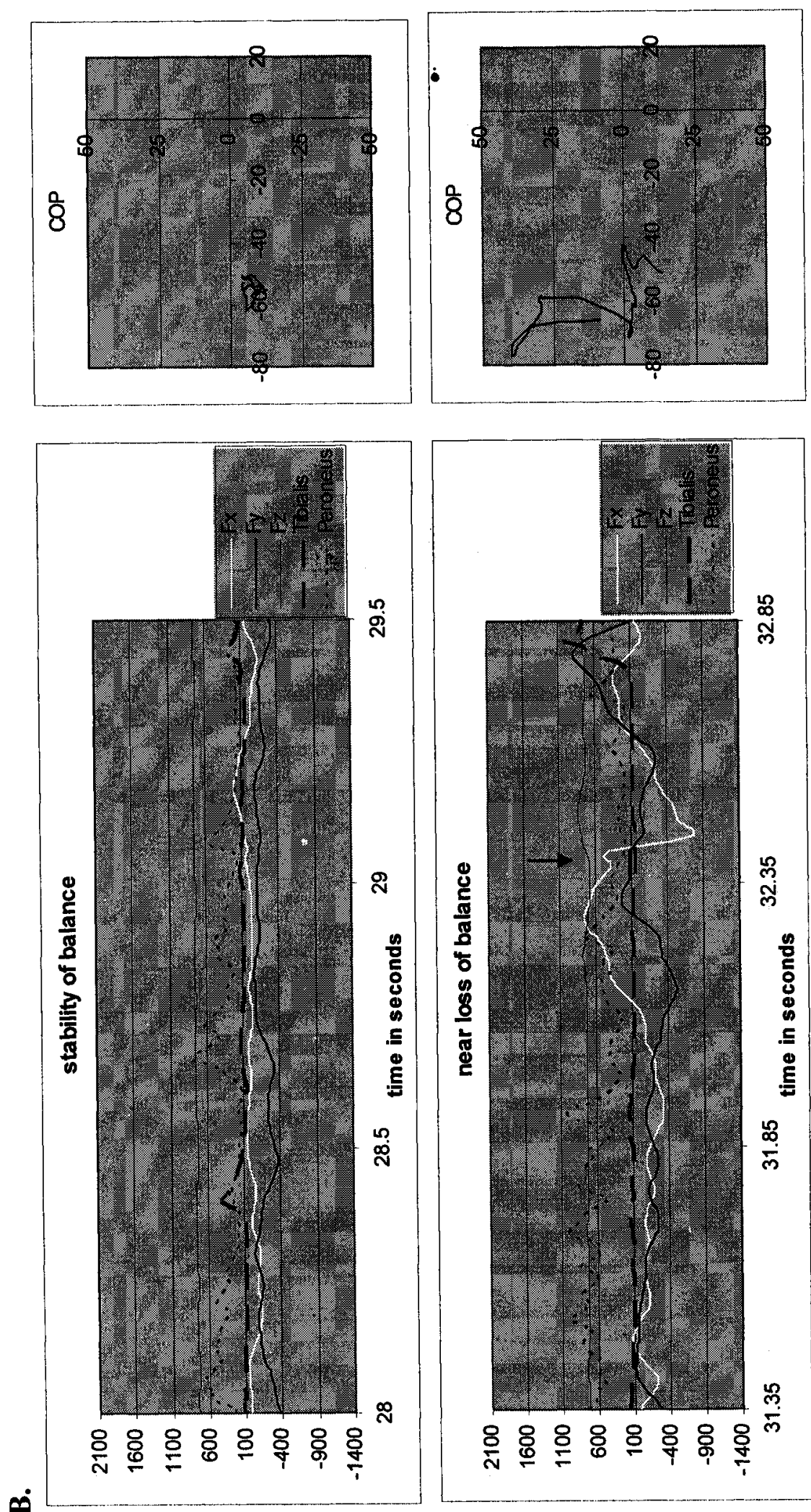

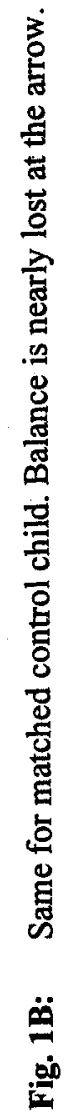


TABLE 2

Cross-correlation ( $p<.01$ for values $>.20$ and $p<.001$ for values $>.26$ ) hetween EMG and force plate signals for $1.5 \mathrm{~s}$ epochs (150 samples) of stable balance (top) and near loss of balance (bottom) for the lower leg muscles and upper leg muscles. Bold figures indicate major group differences.

\begin{tabular}{|c|c|c|c|c|c|c|c|c|c|}
\hline \multirow{2}{*}{$\frac{\text { stable }}{\text { groups }}$} & \multirow[b]{2}{*}{$\mathbf{N}$} & \multicolumn{2}{|c|}{ Tibialis } & \multicolumn{2}{|c|}{ Peroneus } & \multicolumn{2}{|c|}{ Rectus Femoris } & \multicolumn{2}{|c|}{ Semitendinosus } \\
\hline & & $F x$ & Fy & $F x$ & Fy & $F x$ & Fy & $F x$ & Fy \\
\hline $6-8$ years & 12 & 0.25 & $0.48^{*}$ & 0.21 & $0.31^{* *}$ & 0.25 & 0.38 & 0.19 & $0.22^{*}$ \\
\hline $9-11$ years $^{\wedge}$ & 14 & 0.28 & $0.57^{*}$ & 0.22 & $0.51^{* *}$ & 0.24 & 0.32 & 0.21 & $0.33^{*}$ \\
\hline DCD-bp & 13 & 0.37 & $0.41^{\star \star *}$ & 0.25 & 0.46 & 0.21 & $0.16^{* * *}$ & 0.25 & 0.27 \\
\hline Controls^ & 13 & 0.33 & $0.57^{\star \star}$ & 0.22 & 0.49 & 0.22 & $0.37^{\star \star \star *}$ & 0.19 & 0.36 \\
\hline \multicolumn{2}{|l|}{ near loss } & \multicolumn{2}{|c|}{ tibialis } & \multicolumn{2}{|c|}{ Peroneus } & \multicolumn{2}{|c|}{ Rectus Femoris } & \multicolumn{2}{|c|}{ Semitendinosus } \\
\hline groups & $N$ & $F x$ & Fy & $F x$ & Fy & $F x$ & Fy & $F x$ & Fy \\
\hline $6-8$ years & 12 & 0.25 & 0.43 & 0.23 & $0.36^{* \star}$ & 0.19 & 0.20 & 0.16 & 0.28 \\
\hline $9-11$ years $^{\wedge}$ & 14 & 0.27 & 0.45 & 0.20 & $0.48^{\star *}$ & 0.22 & 0.23 & 0.20 & 0.34 \\
\hline DCD-BP & 13 & $0.24^{\star \star}$ & $0.40^{*}$ & 0.27 & $0.36^{\text {** }}$ & 0.26 & 0.22 & 0.22 & $0.25^{\star}$ \\
\hline Controls ${ }^{\wedge}$ & 13 & $0.35^{\star *}$ & $0.48^{*}$ & 0.21 & $0.50^{\star \star}$ & 0.23 & 0.22 & 0.21 & $0.34^{x}$ \\
\hline
\end{tabular}

$\wedge$ these groups share 11 subjects. Levels of significant differences between younger and older group, or between DCD-BP and control group: ${ }^{*} p<.1,{ }^{* *} p<.05,{ }^{* * *} p<.01$

\section{TABLE 3}

Percentage of subjects with significant $(p<0.01)$ correlations for the $1.5 \mathrm{~s}$ epochs of stable balance (left) and close to loss of balance (right). Bold indicates group difference $>20 \%$.

\begin{tabular}{lcccccccccc}
\hline \multicolumn{1}{c}{ stable } & \multicolumn{3}{c}{ Tibialis } & \multicolumn{2}{c}{ Peroneus } & near loss & \multicolumn{2}{c}{ Tibialis } & \multicolumn{2}{c}{ Peroneus } \\
\hline groups & N & Fx & Fy & Fx & Fy & groups & Fx & Fy & Fx & Fy \\
6-7 years & 12 & 45 & 91 & 36 & 64 & $6-7$ years & 41 & 86 & 64 & 82 \\
$9-11$ years $^{\wedge}$ & 14 & 71 & 100 & 43 & 71 & $9-11$ years & 61 & 82 & 43 & 89 \\
DCD-bp & 13 & 69 & 77 & 54 & 69 & DCD-BP & 31 & 81 & 54 & 62 \\
Controls^ $^{\wedge}$ & 13 & 77 & 100 & 46 & 77 & Controls^ $^{\wedge}$ & 73 & 88 & 42 & 88 \\
\hline
\end{tabular}

$\wedge$ these groups share 11 subjects 
feedback loops, that may range from $30 \mathrm{~ms}$ for the M1 reflex to a few hundreds of $\mathrm{ms}$ for higher level processing, was not considered in this analysis. Table 2 summarizes the outcome of the analysis.

Strong correlations are found in each group for lateral control. Older subjects compared with young ones show on average a stronger lateral control for the tibialis, peroneus, and semitendinosus muscles. The children with DCD show a weaker lateral control for the tibialis, peroneus, and upper leg muscles, indicating less efficient control. In contrast, older subjects did show an appropriate reduction of tibialis involvement in the control of Fx when balance is at risk. In the more unstable situation, their correlation pattern resembles that of younger children.

Over a 10 s period, all groups showed a significant correlation $(p<.0001, r>.326)$ between tibialis and peroneus activation and Fy. In the DCD-bp group, this correlation was significant for $81 \%$ of the subjects, whereas for the other groups this was over $90 \%$. The overall percentage of subjects having a significant correlation $(p<0.1)$ with $\mathrm{Fx}$ was $25 \%-31 \%$ for the DCD-bp and younger groups and $14 \%$ for the other groups. Table 3 lists the number of subjects with significant $(p<.01)$ correlations for the $1.5 \mathrm{~s}$ epochs.

In the DCD-bp group, the lower correlation strength between EMG-activation and reactive forces in balance control could be due to an inconsistency in the timing of muscular activation in balance control.

\section{STRUCTURAL DEFICITS ASSOCIATED WITH DCD?}

The cerebellum is important for movement control and plays a particularly crucial role in balance and locomotion (Morton \& Bastian, 2004). This role might point at cerebellar involvement in the motor problems of DCD. The motor problems of children with DCD are varied, however, and without further evidence, such a conclusion is premature.

What evidence is there for a cerebellar deficit that contributes to DCD? Three possible sources of information can help to clear a question like this.

1. Direct evidence from fMRI or electrophysiologcal studies. These are not available yet.

2. Indirect evidence from studies that associate DCD with functional measures assumed to be related to cerebellar function, such as the balance studies reported here.

3. Indirect evidence from disorders comorbid to DCD (Visser, 2003, 2005).

Among the studies that associate DCD with functional measures assumed related to cerebellar function are those using developmental neurological screening tests. Lundy-Ekman et al. (1991) selected two subgroups of children with DCD: a subgroup of children with cerebellar soft neurological signs and a subgroup with soft basal ganglia signs of dysfunction. The children and their controls participated in tasks of timing and force control. The first subgroup performed poorly specifically on timing tasks-timing is assumed a cerebellar function, whereas the second subgroup performed poorly on the force control task, assumed related to basal ganglia function. Volman and Geuze (1998) applied the same neurodevelopmental test (Touwen's test) to divide their group of 24 children with DCD into cerebellar and basal ganglia subgroups. We did not succeed, however, because the distribution of soft neurological signs did not allow classification of the children with DCD into reliable subgroups of cerebellar or basal ganglia dysfunction. Recently $O$ 'Hare and Khalid (2004) investigated the association of abnormal cerebellar function in children with DCD and reading difficulties. In a group of 23 children attending pediatric occupational therapy and diagnosed as DCD all showed soft signs of cerebellar dysfunction. However, according to their Table 4 the mean score of 14 out of 15 
components of the Quick Neurological Screening Test is over the upper limit of 'suspicious' score, with only two components that clearly tap cerebellar function. It seems to me that, although cerebellar soft signs may be present in all children, this is by no means a specific finding, as the many other soft neurological signs indicate the involvement of varied neurological structures.

It should be kept in mind that the perceptualmotor system operates as a distributed network in which the cerebellum plays a functional role. Evidence that the cerebellum is involved in timing processes is mainly derived from studies on finger tapping. Ivry and Keele (1989) reported timing deficits in patients with cerebellar lesions. Rivkin et al. (2003) employed fMRI to study specific activation patterns in the brain during alternating finger tapping in a group of 14 children aged 7.9 to 11.3 years. This timing task activated a neural network involving the primary motor cortex, the supplementary and presupplementary motor area, and parts of the cerebellum. The fMRI data of children with DCD are not available.

Visser $(2003,2005)$ put forward indirect evidence from disorders comorbid to DCD, such as dyslexia (Fawcett \& Nicolson, 1995; Nicolson \& Fawcett, 2001). For example, co-morbidity was reported in a study of children attending pediatric occupation therapy and diagnosed as DCD, parents reporting reading problems in $70 \%$ of cases (O'Hare \& Khalid, 2002). Visser argues that problems of automatization are common in comorbid disorders of dyslexia and DCD, and that this indicates cerebellar involvement in these disorders. Motor problems and abnormalities in muscle tone are common symptoms in the majority of subjects with dyslexia (Nicolson et al., 2001). A major finding reported is an automatization deficit of balance control (Fawcett \& Nicolson, 1992; Yap \& Van der Leij, 1994). Such a deficit will become apparent during the performance of a motor task concurrent with a second non-motor task. According to this dual-task paradigm, a decrease in performance compared with the performance of the single-task condition indicates a lack of automatization of the primary (balance) task. The findings led Fawcett and colleagues to conclude that dyslexia is caused by a general deficit in the ability to automatize fully the skills that affect both reading proficiency and automatized motor skill. Nicolson and Fawcett relate the lack of automatization to cerebellar dysfunction.

\section{CONCLUSION}

Many children with DCD show poor postural and balance control, especially in extremely difficult situations. The characteristics of this poor control are likely to be task dependent-especially task difficulty and the availability of sensory information will influence the quality of postural and balance control. The major characteristics of poor control in DCD are an inconsistent timing of muscle activation sequences, co-contraction, a lack of automatization, and slowness of response. Converging evidence indicates that cerebellar dysfunction contributes to the motor problems of children with DCD.

\section{REFERENCES}

American Psychiatric Association. 1994. Diagnostic and Statistical Manual of Mental Disorders DSMIV-TR . $4^{\text {th }}$ ed. Washington, DC, USA: APA.

Fawcett AJ, Nicolson RI. 1992. Automatization deficits in balance for dyslexic children. Percept Mot Skills 75: 507-529.

Forssberg H, Nashner LM. 1983. Ontogenetic development of postural control in man: adaptation to altered support and visual conditions during stance. J Neurosci 2: 545-552.

Forseth AK, Sigmundsson H. 2003. Static balance in children with hand-eye co-ordination problems. Child Care Health Dev 29: 569-579.

Foudriat BA, Di Fabio, RP, Anderson JH. 1993. Sensory organization of balance responses in children 3-6 years of age: a normative study with 
diagnostic implications. Int $\mathbf{J}$ Pediatr Otorhinolaryngol 27: 255-271.

Geuze RH. 2003. Static balance problems in children with Developmental Coordination Disorder. Hum Move Sci 22: 527-548.

Geuze RH. 2005a. Charactéristiques du trouble d'acquisition des coordinations motrices: de problèmes et pronostiques (Characteristics of DCD: on problems and prognosis). In: Geuze RH, ed, Le trouble de l'acquisition de la coordination. Evaluation et rééducation de la maladresse chez l'enfant (Developmental Coordination Disorder. A review of current approaches). Collection Troubles du développement psychologique et des apprentissages. Marseille, France: Solal Éditeurs.

Geuze RH. 2005b. Motor impairment in DCD and activities of daily living. In: Sugden, D, Chambers $\mathrm{M}$, eds, Children with Developmental Coordination Disorder. London, UK: Whurr Publ.

Geuze RH, Jongmans MJ, Schoemaker MM, SmitsEngelsman BCM. 2001. Clinical and research diagnostic criteria for Developmental Coordination Disorder. Hum Move Sci 20: 7-47.

Gillberg IC, Gillberg C. 1988. Children with deficits in attention, motor control and perception (DAMP): need for specialist treatment. Acta Paediatr Scand 77: $450-451$.

Hadders-Algra M. 2003. Developmental Coordination Disorder: Is clumsy motor behavior caused by a lesion of the brain at early age? Neural Plast 10: 39-50.

Henderson SE, Sugden DA. 1992. Movement Assessment Battery for Children. Sidcup, UK: The Psychological Corporation.

Ivry RB, Keele SW. 1989. Timing functions of the cerebellum. J Cogn Neurosci 1: 136-152.

Johnston LM, Burns YR, Brauer SG, Richardson CA. 2002. Differences in postural control and movement performance during goal directed reaching in children with Developmental Coordination Disorder. Hum Move Sci 21: 583-601.

King DL, Zatsiorsky VM. 2002. Periods of extreme ankle displacement during one-legged standing. Gait Posture 15: 172-179.

Kirshenbaum N, Rich CL, Starkes JL. 2001. Nonlinear development of postural control and strategy use in young children: a longitudinal study. Exp Brain Res 2001. 140: 420-431.

Landgren $\mathrm{M}$, Pettersson R, Kjellman B, Gillberg C. 1996. ADHD, DAMP and other neurodevelopmental/psychiatric disorders in six-year-old children: Epidemiology and co-morbidity. Dev Med Child Neurol 38: 891-906.

Laszlo JI, Sainsbury KM. 1993. Perceptual-motor development and prevention of clumsiness. Psychol Res 1993. 55: 167-174.

Lundy-Ekman L, Ivry R, Keele SW, Woollacott, MH. 1991. Timing and force control deficits in clumsy children. J Cogn Neurosci 3: 367-376.

Morton SM, Bastian AJ. 2004. Cerebellar control of balance and locomotion. Neuroscientist 10: 247259.

Nicolson RI, Fawcett AJ, Dean P. 2001. Developmental dyslexia: The cerebell ar deficit hypothesis. Trends Neurosci 24: 508-511.

O'Hare A, Khalid S. 2002. The association of abnormal cerebellar function in children with developmental coordination disorder and reading difficulties. Dyslexia 8: 234-248.

Przysucha EP, Taylor MJ. 2004. Control of stance and Developmental Coordination Disorder: The role of visual information. APAQ 21: 19-33.

Raynor, AJ. 1998. Fractioned reflex and reaction time in children with developmental coordination disorder. Motor Control 2: 114-124.

Rivkin MJ, Vajapeyam S, Hutton C, Weiler ML, Hall EK, Wolraich DA, et al. 2003. A functional magnetic resonance imaging study of paced finger tapping in children. Pediatr Neurology 28: 89-95.

Shumway-Cook A, Woollacott MH. 1985. The growth of stability: Postural control from a developmental perspective. J Mot Behav 17, 131-147.

Shumway-Cook A, Woollacott MH. 1990. Development of postural control. In: Woolllacott $\mathrm{MH}$ Shumway-Cook A, eds, Development of Posture and Gait across the Life Span. $2^{\text {nd }}$ ed. Columbia, South Carolina: University of South Carolina Press; 143-168.

Smits-Engelsman BCM. 1998. Handleiding [Dutch manual] Movement Assessment Battery for Children. Lisse, the Netherlands: Swets \& Zeitlinger.

Thelen E, Fisher DM, Ridley-Johnson R. 1984. The relationship between physical growth and a newborn reflex. Infant Behav Dev 7: 479-493.

Usui N, Maekawa K, Hirasawa Y. 1995. Development of the upright postural sway of children. Dev Med Child Neurol 37, 985-996.

Visser J. 2003. Developmental coordination disorder: a review of research on subtypes and comorbidities. Hum Move Sci 22:479-493.

Visser J. 2005. Sous-types et comorbidités du Trouble de l'Acquisition de la Coordination. 
[Subtypes and comorbidities of DCD.] In: Geuze $\mathrm{RH}$, ed, Le trouble de l'acquisition de la coordination. Evaluation et rééducation de la maladresse chez l'enfant (Developmental Coordination Disorder. A Review of Current Approaches). Collection Troubles du développement psychologique et des apprentissages. Marseille, France: Solal Éditeurs.

Volman MJM, Geuze RH. 1998. Relative phase stability of bimanual and visuomanual rhythmic coordination patterns in children with a Developmental Coordination Disorder. Hum Move Sci 17, 541-572.

Wann JP, Mon-Williams M, Rushton K. 1998. Postural control and co-ordination disorders: The swinging room revisited. Hum Move Sci 17, 491-513.
Williams HG, Fisher JM, Tritschler KA. 1983. Descriptive analysis of static postural control in 4, 6 , and 8 year old normal and motorically awkward children. Am J Phys Med 62, 12-26.

Wilson PH, McKenzie BE. 1998. Information processing deficits associated with Developmental Coordination Disorder: A meta-analysis of research findings. J Child Psychol Psychiatry 39: 829-840.

World Health Organization, 1992. The ICD-10 Classification of Mental and Behavioral Disorders. Clinical Descriptions and Diagnostic Guidelines. Geneva, Switzerland: WHO.

Yap RL, van der Leij A. 1994. Testing the automatization deficit hypothesis of dyslexia via a dual-task paradigm. J Learn Disabil 27, 660-665. 

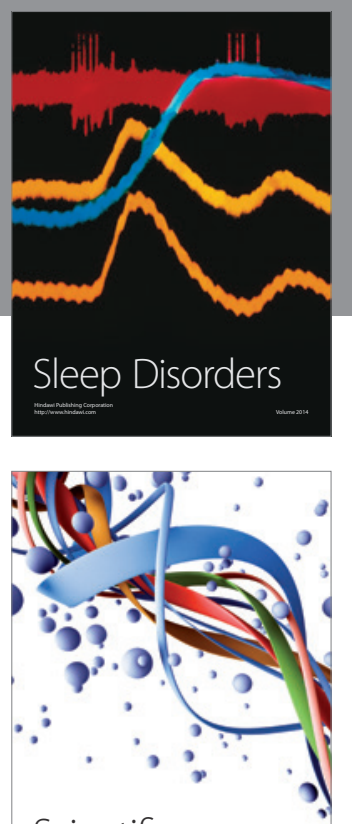

Scientifica
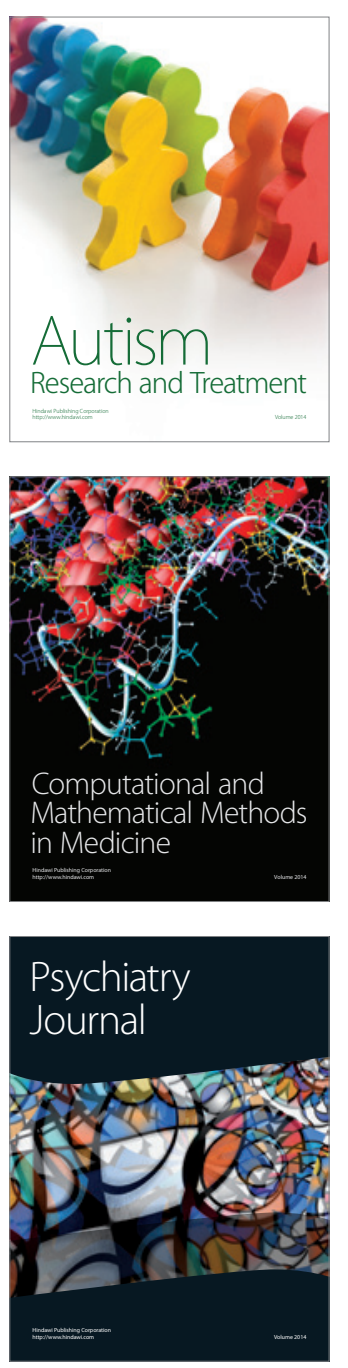
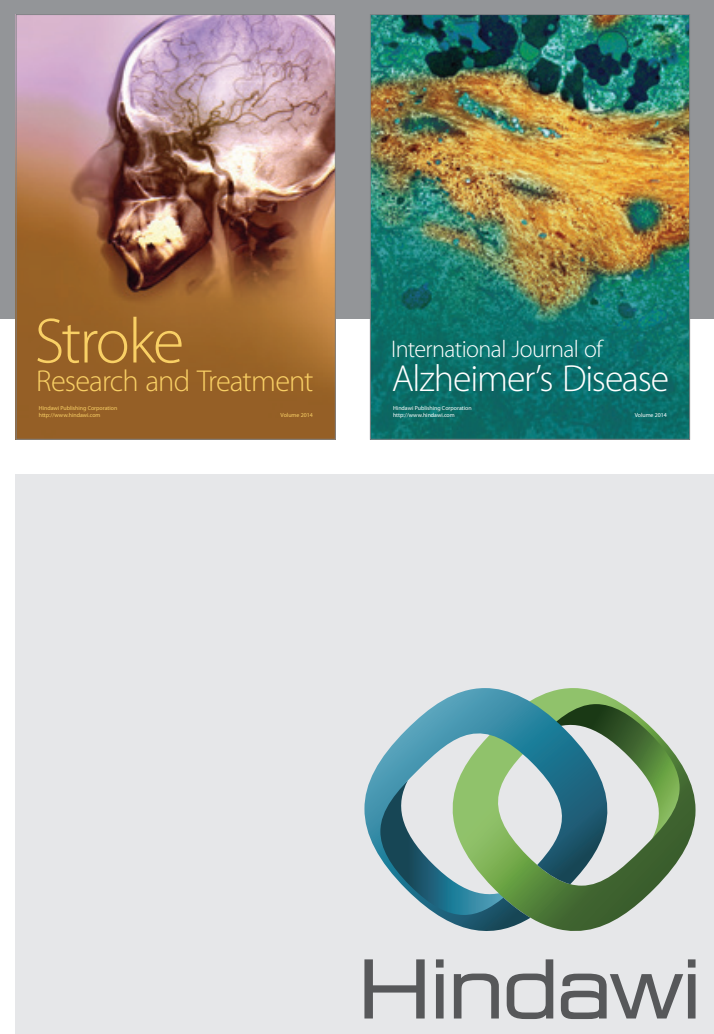

Submit your manuscripts at

http://www.hindawi.com
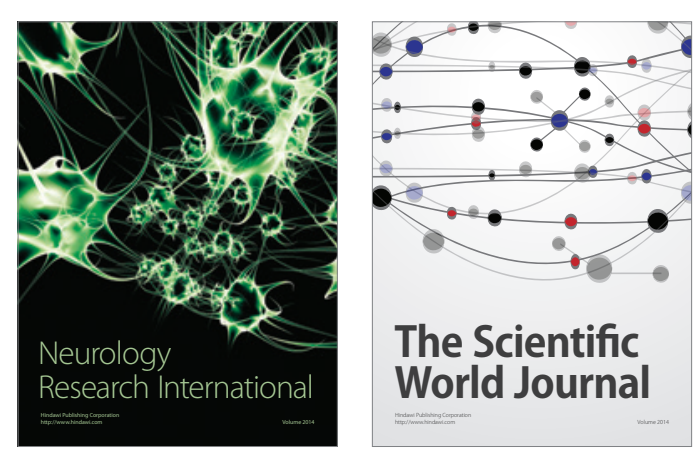

The Scientific World Journal

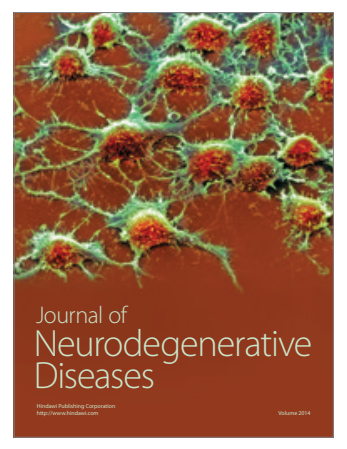

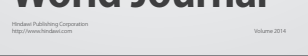

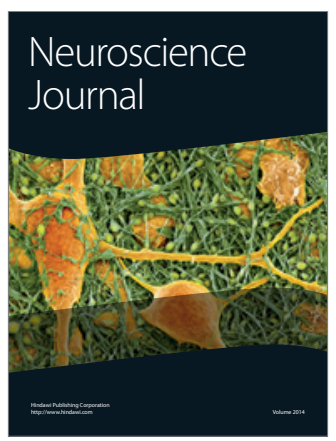

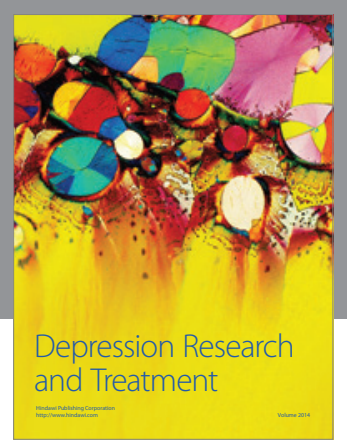
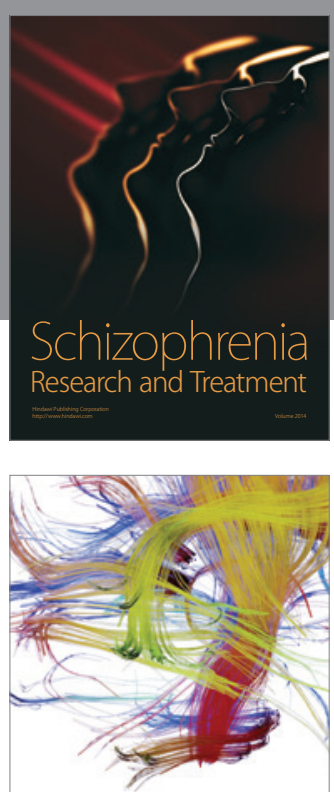

Brain Science

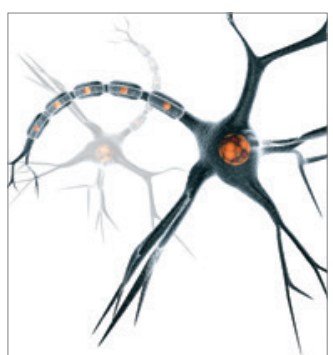

Neural Plasticity
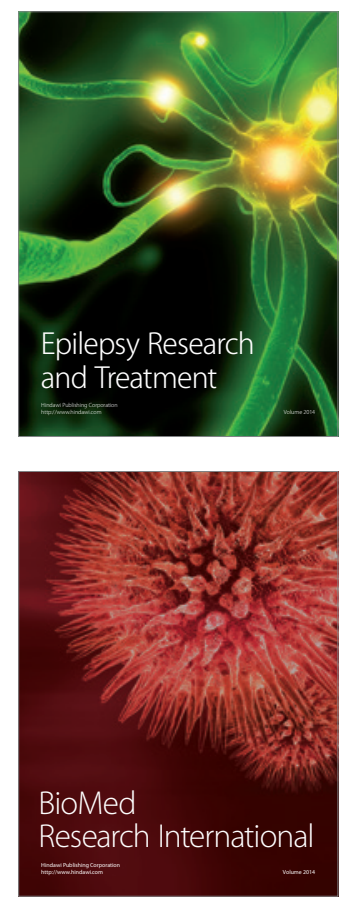

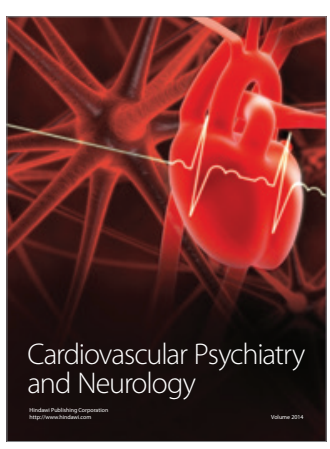

Parkinson's

Disease
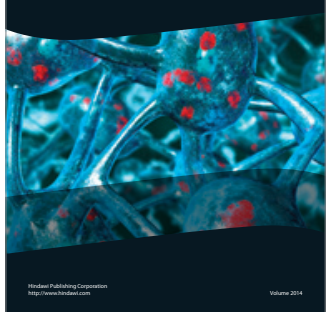